\title{
Influence of rainfall on the noise shielding by a green roof
}

\author{
T. Van Renterghem*, D. Botteldooren
}

Ghent University, Department of Information Technology, Sint-Pietersnieuwstraat 41, B-9000 Gent, Belgium

*Corresponding author. Tel.: +32 926436 34; fax: +32 926499 69. E-mail address: timothy.van.renterghem@intec.ugent.be

\begin{abstract}
The potential of a green roof to reduce diffracting sound waves towards a shielded side of a building has been assessed before by both in-situ and laboratory experiments, and by numerical simulations. However, like any porous material, the acoustic performance of the green roof's substrate could suffer from the presence of water. A 46-day lasting controlled sound propagation experiment was set up near the edge of a 6-m tall building equipped with an extensive green roof, having a substrate thickness of 7 $\mathrm{cm}$. At selected moments, test signals were emitted, allowing to monitor the attenuation between a reference microphone and a microphone at low height positioned on the green roof (at $15.3 \mathrm{~m}$ from the roof's edge). Meteorological parameters and the green roof's substrate moisture content were continuously measured. Sound diffracting over a green roof showed to be sensitive to the substrate moisture content in a specific sound frequency range, more precisely between $250 \mathrm{~Hz}$ and $1250 \mathrm{~Hz}$. The difference in noise attenuation between a rather dry state $\left(0.1 \mathrm{~m}^{3} / \mathrm{m}^{3}\right)$ of the substrate and the maximum observed volumetric water content (close to saturation, $0.33 \mathrm{~m}^{3} / \mathrm{m}^{3}$ ) could range up to $10 \mathrm{~dB}$. However, calculations show that the impact of the water content in an extensive green roof substrate for the specific case of road traffic noise abatement is expected to be limited.
\end{abstract}

keywords : green roof, noise, shielding, moisture, building envelope 


\section{I.Introduction}

The environmental, ecological and economic benefits of green roofs are manifold. The reader is referred to a number of review articles for an overview [1][2][3][4][5]. During the last decade, the noise reduction was recognized as an additional benefit. Scientific research points e.g. at the increased acoustic roof insulation provided by a green roof [6][7]. Of most practical interest is the ability of green roofs to reduce sound waves diffracting over buildings or parts of buildings [8][9][10][11]. A green roof, in contrast to common rigid building envelopes, could therefore help making a facade really silent, on condition that the dominant sound path between source and (shielded) facade interacts with the green roof. This is important in the view of the so-called quiet side effect that has shown to reduce noise annoyance and noise-induced sleep disturbance [12][13][14][15].

Two numerical studies with full-wave techniques [8][9] initially showed that green roofs significantly reduce the intensity of diffracting sound waves when opposed to rigid roofs. In addition, green roofs were found to have the highest potential for road traffic noise abatement among other building envelope greening measures in a typical urban setting [16]. The in-situ experiments reported in Ref. [10] allowed measuring the real noise insertion loss of extensive green roofs, since measurements were performed before and after their placement. Measurements under controlled laboratory conditions [11] confirmed the efficiency of green roofs in reducing diffracting sound waves over low-profiled structures.

Adding water to any porous material deteriorates its absorbing properties. This effect has been studied in case of common soils. In general, the acoustic impedance increases (or the absorption coefficient decreases) with increasing moisture content [17][18][19][20]. This decreased absorption in soils is caused by the reduced effective layer thickness of the porous medium when the mean water level increases. The soil therefore acts as a hard-backed layer. This is especially true when gravitational forces dominate capillary forces after a rainfall event. In addition, infiltration of water might lead to a decrease in porosity by swelling of soil particles that absorb water. Also clogging of pores might prohibit sound entering the soil [18], the latter being essential to benefit from absorption of sound. Even adding small amounts of water was shown to potentially lead to strong changes in the acoustic surface admittance of sand [19] or specific flow resistance of various types of soils [17]. In the limit, when all air voids are filled with water, the soil surface must approach that of a perfect reflector for sound waves [18]. In addition, complex layering effects, especially at higher frequencies, have been observed [18]. Similar to natural soils, green roof substrates are negatively effected by the presence of water: Impedance tube measurements showed a decrease in absorption coefficient (at normal incidence) with increasing moisture content [21].

However, sufficient water retention in green roofs is important, and is often the main motive for placing a green roof on a building: Runoff peaks to the sewers are reduced, smoothened out and delayed. A green roof therefore helps in reducing flooding risks [2][22][23][24][25][26]. The green roof layer buildup is often adapted based on the local needs. In some cases, an additional water retention fabric (e.g. a mineral wool mat) is added in between the bottom of the substrate layer and the top of the water drainage layer. This means that water retention might conflict with the acoustical absorption provided 
by a green roof. In addition, thermal insulation will be negatively affected by the presence of water in the substrate as well [3].

This work aims at building up knowledge on how the acoustic shielding by a green roof is affected by rainfall. Its dynamics are of practical interest if one wants to apply a green roof as a noise reducing measure. A real-life controlled monitoring campaign has been set up. Note that previously reported simulations and measurements, showing the potential of green roofs to abate noise, were mainly performed in case of rather dry substrates, leading to maximally observed effects. Knowledge about the influence of moisture on substrates in laboratory conditions cannot be directly translated to practice, as sound waves shear over the green roof, in contrast to the normal incidence plane-wave approach in e.g. an impedance tube [21].

\section{EXPERIMENTAL SETUP}

\section{A. Site description}

\section{General}

The measurements were conducted near the edge of a rectangular building equipped with a green roof (Kontich, Belgium). A cross-section and plan view of the experimental site is depicted in Fig. 1. A reference microphone M1 (height of the microphone membrane was $1.7 \mathrm{~m}$ ) and a loudspeaker were positioned next to the building's facade at ground level (see Fig. 2). Microphone M2 was placed on the green roof, near its centre, along the line loudspeaker-M1, involving $15.3 \mathrm{~m}$ propagation over the green roof (see Fig. 3). The height of the membrane of microphone M2, relative to the green roof, was at 0.43 $\mathrm{m}$. Such a low height was chosen to avoid shifts in interference pattern due to changes in the absorbing properties of the green roof, leading to non-straightforwardly interpretable results. Furthermore, such a low receiver height is most relevant for the sound pressure levels in situations where a double diffraction (so over two subsequent roof edges) is to be expected. 
(a)
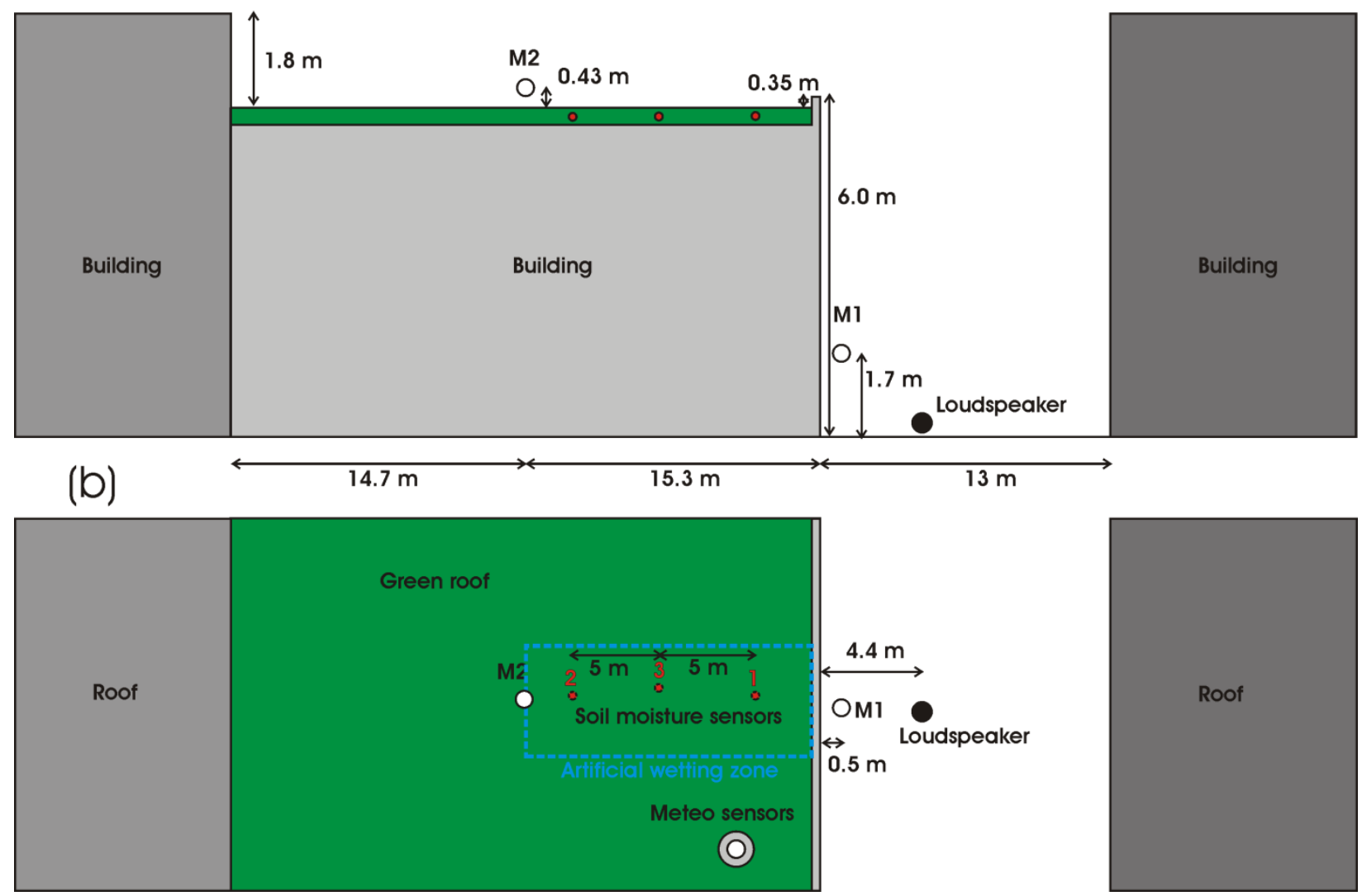

Fig. 1. Positioning of the instrumentation at the experimental site : (a) cross section (not true to scale), (b) plan view.

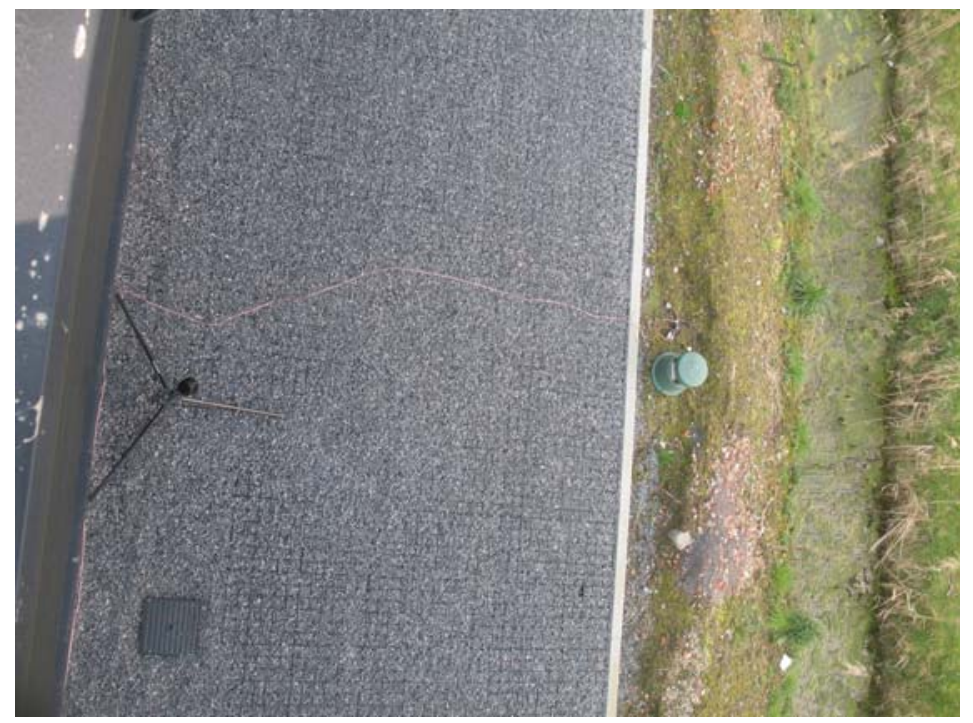

Fig. 2. Picture taken from the edge of the roof showing the reference microphone (M1) and the outdoor loudspeaker. 


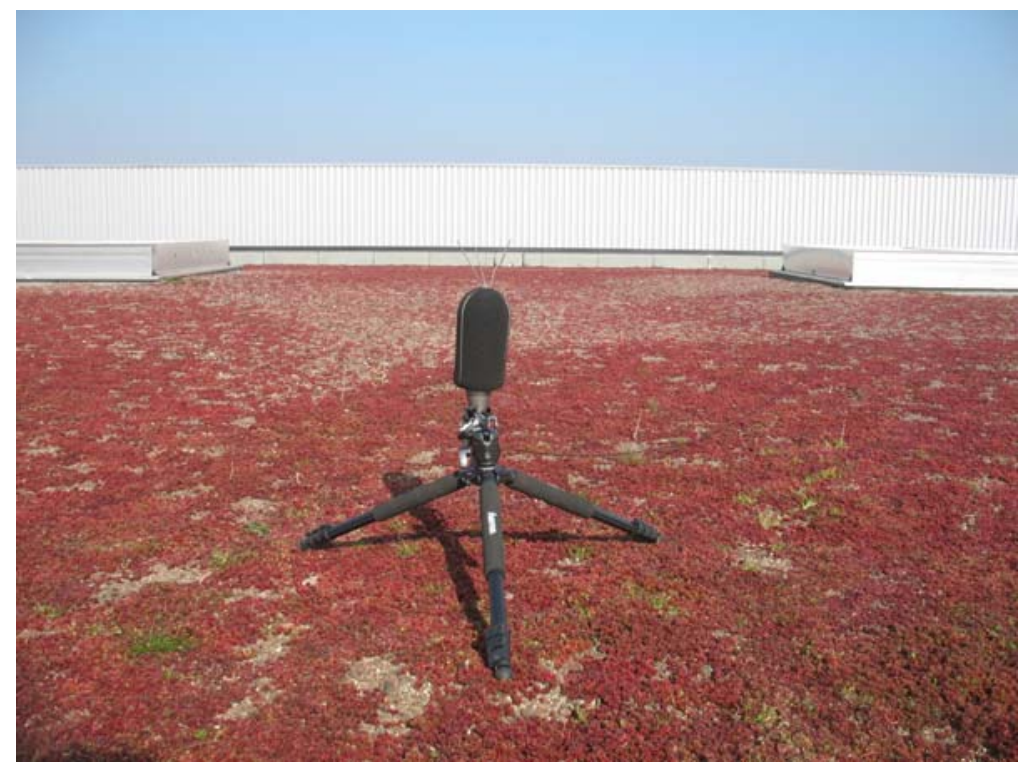

Fig. 3. Picture taken from microphone 2, positioned at low height on the green roof, towards the edge of the roof closest to the loudspeaker.

The reference microphone M1 was used to account for possible variations in the emitted source power level over time. The acoustic parameter of concern is the difference in sound pressure level between microphone 1 and microphone 2, further indicated as "attenuation". The positions of the loudspeaker and the microphones were fixed throughout the experiment; the variation in shielding due to changing (meteorological) conditions over time could therefore be directly assessed.

A parallel wall from a nearby building is located at a distance of approximately $12.5 \mathrm{~m}$ relative to microphone 1 . At $14.7 \mathrm{~m}$ from microphone $\mathrm{M} 2$, the green roof was bordered with an elevated part of the building (see Fig. 1). The roof edge, closest to the loudspeaker, was slightly elevated (approximately $0.35 \mathrm{~m}$ relative to the green roof top surface). As a result, sound propagation towards microphone 2 will not result in a pure single-edge diffraction.

\section{Green roof}

The extensive green roof under study is built up as follows. A drainage fabric (DBGS DRAIN 8) with a thickness of $8 \mathrm{~mm}\left(0.7 \mathrm{~kg} / \mathrm{m}^{2}\right)$ is placed below the substrate layer, consisting of a roof protection membrane, a curved drainage layer and a filter membrane to prevent loss of substrate. The latter consists of a non-woven polypropylene geotextile (thickness of $0.9 \mathrm{~mm}, 100 \mathrm{~g} / \mathrm{m}^{2}$ ). The core of the drainage fabric consists of channels to evacuate water and is made of polypropylene as well. The constant-head water flow capacity within the plane of the material (measured following EN ISO 1295), at an inclination of $4 \%$, is equal to $0.12 \mathrm{l} / \mathrm{s} . \mathrm{m}$ (at a normal, compressive stress of $200 \mathrm{kPa}$ ). The roof inclination is estimated to be $2-3 \%$.

The substrate (XF200) follows the guidelines issued by FLL (Forschungsgesellschaft Landschaftsentwicklung Landschaftsbau e.V.) and has a thickness of $7 \mathrm{~cm}$. The main content of the 
substrate is the mineral fraction (between $70 \%$ and $90 \%$ ); the organic content is between $3 \%$ and $8 \%$. The water-permeability of the substrate exceeds $0.001 \mathrm{~cm} / \mathrm{s}$. The maximum granule diameter is $12 \mathrm{~mm}$.

The vegetation layer consist of sedum shoots of various species like Sedum alba, S. acre, S. sexangulare, S. reflexum and S. spurium. The average sedum cover ratio along the sound propagation path is estimated to be near $65 \%$. The thickness of the sedum layer is smaller than roughly $3 \mathrm{~cm}$.

The specifications of the green roof provided in this section are those found in the product sheets provided by the supplier.

\section{B. Acoustical instrumentation}

A 4-channel monitoring system (Swing, from Sinus Messtechnik $\mathrm{GmbH}$ ) was used, ensuring time synchronization between the measurements at both microphones. Since only 2 channels were used, the extended dynamic range option could be employed. The Sinus Measurement Toolbox (SMT) for Matlab was used to control the measurement cycles, consisting in emitting a sound sample at predefined moments and consequently recording at the 2 microphones. Recordings were made at a sample frequency of $51.2 \mathrm{kHz}$, with 1/2" condenser measurement microphones (MK250, Microtech Gefell). Preamplifiers (SV12, Svantek) completed the measurement chain. Weather proof outdoor units (WME 950, Microtech Gefell) with birdspikes were used. At the startup of the experiment, an in-situ calibration was performed with a class 1 pistonphone emitting a single sound frequency of $1 \mathrm{kHz}$ at $94 \mathrm{~dB}$ (SV30A, Svantek). At the end of the experiment, calibration was checked and yielded deviations in the range -0.4 to $0.1 \mathrm{~dB}$, which was considered to be acceptable.

A Bose freespace 360P series II outdoor loudspeaker was used to emit test signals. This cylinder-like loudspeaker has a diameter of $37 \mathrm{~cm}$ and a height of $38 \mathrm{~cm}$. It has a $360^{\circ}$ horizontal radiation pattern; in vertical direction, the $-6 \mathrm{~dB}$ point is limited to $50^{\circ}$ at $1 \mathrm{kHz}$. The loudspeaker was driven by a QSC 1310 amplifier, fed by the output channel of the monitoring station.

\section{Meteorological and soil moisture observations}

Standard meteorological data was gathered in-situ (Davis Vantage pro 2 weather station), of which the amount of rainfall (resolution of $0.25 \mathrm{~mm}$, accuracy of $4 \%$ ), relative humidity (resolution of $1 \%$, accuracy of $3 \%$ ) and air temperature (resolution of $0.1{ }^{\circ} \mathrm{C}$, accuracy of $0.5^{\circ} \mathrm{C}$ ) were most relevant for the current study. The relative humidity and air temperature sensors were positioned in a radiation shield. These (integrated) sensors were placed on the roof, but sufficiently far away from the line loudspeakerM1-M2 to avoid shielding or scattering of sound by this device. A measurement interval of 5 minutes was used. Wind speed and wind direction were not monitored at the measurement site, but were obtained by consulting 2 standard meteorological observation posts, each at about $10 \mathrm{~km}$ from the experimental site (hourly-averaged data).

Three soil moisture sensors (Decagon EC-5 capacitance sensors, in combination with Decagon datalogger EM50) were used to monitor the volumetric water content in the green roof substrate. The sensors were horizontally inserted in the substrate at a depth of approximately $3.5 \mathrm{~cm}$, along the line 
loudspeaker-M1-M2. The volume of sensitivity, which is an ellipsoidal cylinder centered around the prongs of the sensor with a volume of approximately $18 \mathrm{~cm}^{3}$ [27], is rather small and is located fully inside the substrate layer. Following the product sheets, an accuracy of $3 \%$ volumetric water content (VWC) is guaranteed when using a standard calibration function (in this case, the one provided for perlite was used). The distance between the sensors was about $5 \mathrm{~m}$. Sensor number 3 was placed later on during the experiment in between sensors 1 and 2 (see Fig. 1). The sampling period was chosen to be 1 minute.

\section{D.Acoustic signal processing}

During the 46-day lasting experiment, test signals were emitted on a regular basis to measure the attenuation between M1 and M2. A logarithmic frequency sweep was used, covering the frequency range to constitute the $1 / 3$-octave bands between $100 \mathrm{~Hz}$ and $3.15 \mathrm{kHz}$; the duration of a single sweep was $20 \mathrm{~s}$. Once an hour, a series of 5 sweeps were consecutively emitted (with an interval of $5 \mathrm{~s}$ ). Next, the recorded sweeps were cross-correlated with the signal sent to the amplifier and these 5 calculated cross-correlation functions were linearly averaged afterwards. A Hanning time window around the expected time-of-arrival at each microphone was applied to the averaged cross-correlated signal. In a next step, a Fourier transform was calculated to transfer the data to the frequency domain and results were summarized as 1/3-octave bands. In a final step, the difference in sound pressure level between $\mathrm{M} 1$ and $\mathrm{M} 2$ yielded the attenuation spectrum for a specific hour. A similar signal processing procedure was employed successfully in a noisy, highly shielded outdoor environment [28].

The volume of the amplifier driving the outdoor loudspeaker was tuned to have a sufficient signal-tonoise ratio; however, care was taken not to annoy workers in the office building where the experiment took place or in the direct vicinity of the loudspeaker. For this reason, the output volume had to be limited. In addition, signals were mainly emitted during the evening, night and early morning, and during the weekends. At working days during daytime, the emission of signals was limited to 2 moments only.

\section{E. Wetting experiment}

In addition to analyzing the sound attenuation due to changes in soil moisture content as a result of natural precipitation, an artificial wetting experiment was conducted after the continuous monitoring period was finished. The aim was covering the full range of possible soil moisture contents of the substrate. Water was manually sprayed over the zone relevant for sound propagating towards the second microphone (over about $90 \mathrm{~m}^{2}$, indicated in Fig. 1 with the dashed "wetting zone"). The soil moisture content was monitored during wetting until convergence was reached. Water was added at a low flow rate and as uniformly as possible. At 4 moments, the attenuation was measured with the same procedure as discussed before.

\section{Basic analysis of dataset}

\section{A.Signal-to-noise ratio}


The above described signal processing approach was found to be essential to increase the signal-tonoise ratio, given the fact that the output level of the loudspeaker had to be limited. Furthermore, at the highest sound frequencies considered, the attenuation between the two microphones exceeded $40 \mathrm{~dB}$. Another reason is that the measurements were not performed in a quiet environment (e.g. birds, noise from a major road at about $200 \mathrm{~m}$, air conditioning units on the roof, etc.). As a result, the signal-tonoise ratio varied largely throughout the experiment. Therefore, in a final step, only measurements with a signal-to-noise ratio exceeding $7.5 \mathrm{~dB}$ (over the full frequency range of the sweep, and based upon the cross-correlated signal) were retained in the dataset. This somewhat arbitrary limit can be considered as a good balance between measurement accuracy and retaining a fair amount of data. Setting this condition lead to the rejection of $23 \%$ of the datapoints. In total 523 datapoints (hours) were retained with attenuation data over all 1/3-octave bands between $100 \mathrm{~Hz}$ and $3150 \mathrm{~Hz}$, in combination with meteorological and soil moisture data. The distribution of the signal-to-noise ratios over the full dataset is shown in Fig. 4.

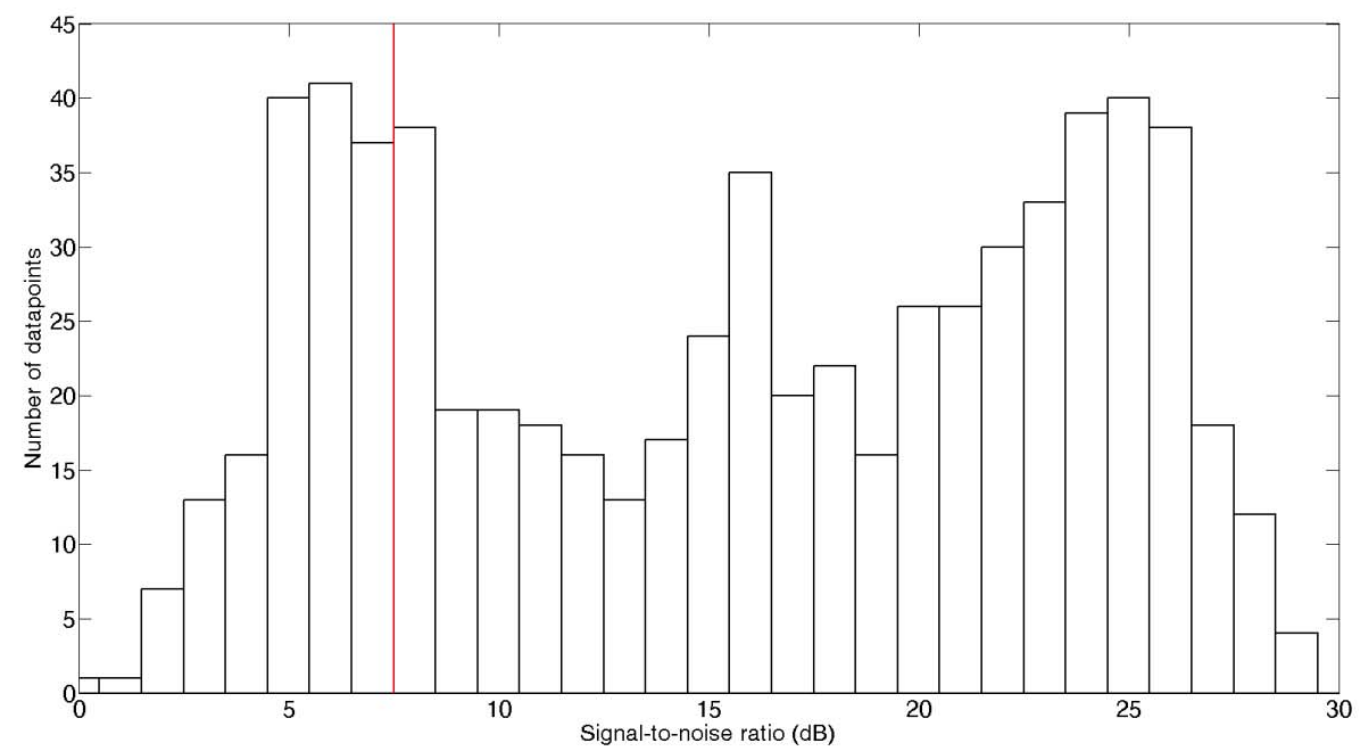

Fig. 4 Distribution of the signal-to-noise ratios over the full dataset. The minimum criterion of $7.5 \mathrm{~dB}$ is indicated with the vertical line.

\section{B.Rainfall and soil moisture content}

During the monitoring period (March-April 2014), the total amount of rainfall was $23.2 \mathrm{~mm}$; during 49 intervals of 5 minutes each, the detection limit of the pluviometer (i.e. $0.25 \mathrm{~mm}$ ) was exceeded. Periods with more intense rainfall (>0.25 $\mathrm{mm}$ per $5 \mathrm{~min}$ interval) were rare, but contributed to $12.95 \mathrm{~mm}$ during the experiment, with a maximum of $3.3 \mathrm{~mm}$ (per $5 \mathrm{~min}$ interval).

The measured VWC at the 3 sensors ranged from $0.09 \mathrm{~m}^{3} / \mathrm{m}^{3}$ to $0.29 \mathrm{~m}^{3} / \mathrm{m}^{3}$ due to natural precipitation. The soil moisture content is not a uniform property of the green roof's substrate. The substrate characteristics, the substrate thickness and sedum cover might change locally. In addition, sensor 1 was 
positioned downstream sensor 3 and 2 (when considering the roof inclination, albeit limited). General trends are followed, nevertheless. A detailed representation of the soil moisture content at the 3 sensors in response to some rainfall events is shown in Fig. 5.

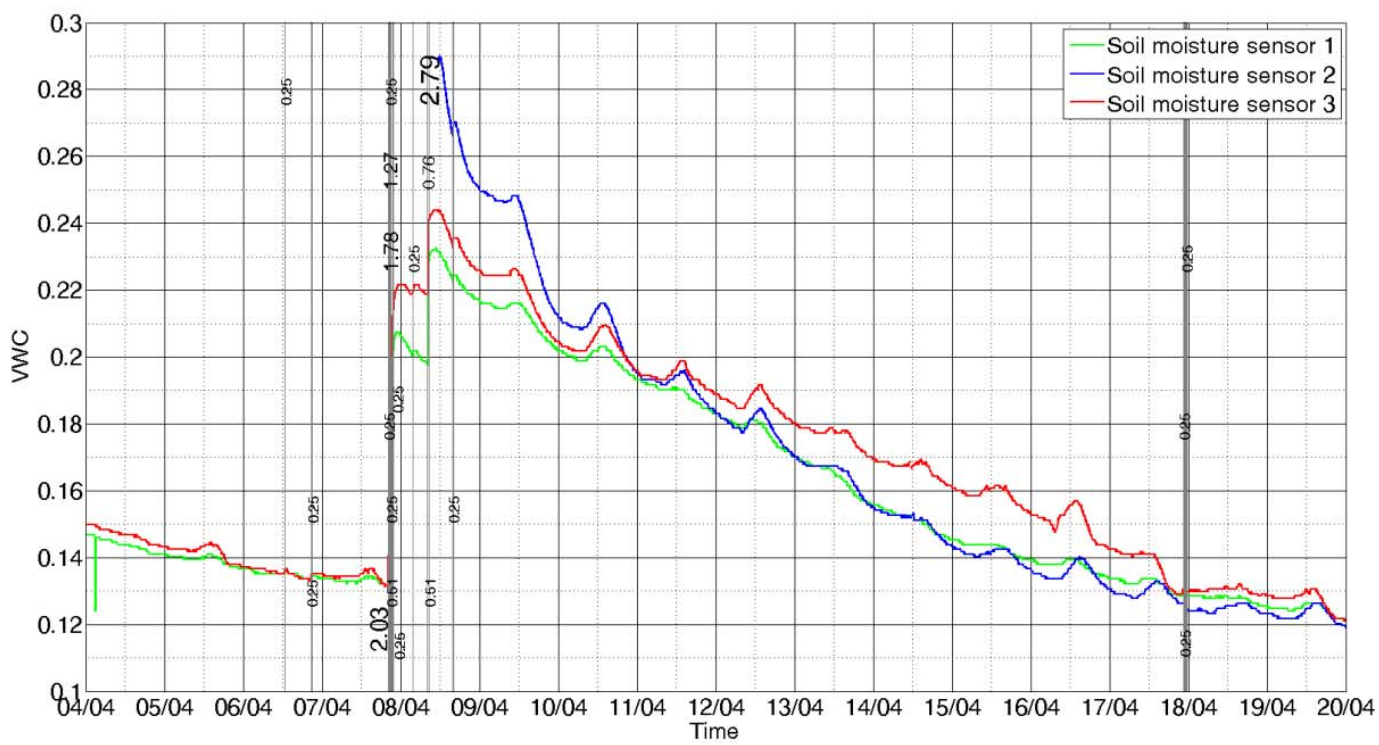

Fig. 5. Detail of the measured green-roof substrate's volumetric water content (in $\mathrm{m}^{3} / \mathrm{m}^{3}$ ) at the 3 probes (at a temporal resolution of $1 \mathrm{~min}$ ) near the intense rainfall at April, 8. The vertical gray lines indicate the moments where rainfall was recorded; the numbers near each line indicate the amount of rainfall (in $\mathrm{mm}$ ) integrated over 5minute intervals.

Hours where rainfall was measured were not retained in the dataset since wet windscreens could alter the acoustic response. However, additional subsequent hours were not removed, as the attenuation is defined as the sound pressure level difference between two microphones with an identical wind screen. As a result, the potentially changed response by the windscreen would cancel out (to some extent). In addition, detailed analysis of the effect of rainfall on common windscreens [29] showed that below 1 $\mathrm{kHz}$, effects could be neglected anyhow, even in case of strong rainfall events. During the artificial wetting experiment, care was taken not to moisten the windscreens, to fully exclude wet windscreen effects.

\section{C.Wind speed and wind direction}

Since $M 2$ is located in an acoustic shadow zone, turbulence scattering could significantly influence the sound propagation [30]. At sound frequencies above $1 \mathrm{kHz}$, the attenuation was found to increase with wind speed (not shown), independent of the wind direction. The main reason for the latter is the loss of coherence, leading to virtually higher attenuations when averaging cross-correlations of the different repetitions at a specific hour [28]. The latter adds to the variability in the measured attenuations. However, such effects occur at sound frequencies where substrate moisture content does not influence the sound attenuation (see further), and will therefore not be analyzed. The wind speed was found to be 
fully independent of the signal-to-noise ratio (larger than $7.5 \mathrm{~dB}$ ), indicating that wind-induced microphone noise is not an issue in the current set of measurements. Note that the microphones were beneficially placed to prevent recording wind noise, either close to the facade of the building, or at limited height above the roof. In addition, the wind speeds were rather limited during the monitoring period $(95 \%$ of the data $<5 \mathrm{~m} / \mathrm{s}$ ).

\section{D.Air temperature and relative humidity}

The measured on-site (hourly-averaged) relative humidity values ranged from $30 \%$ to $93 \%$; relative humidities between $80 \%$ and $90 \%$ were most frequently met ( $34 \%$ in the final dataset). The (hourlyaveraged) air temperature measured on the roof ranged from $0.3^{\circ} \mathrm{C}$ to $25.4{ }^{\circ} \mathrm{C}$, and approaches a normal distribution with a median value of $10.9^{\circ} \mathrm{C}$.

Relative humidity does not influence sound attenuation between microphone 1 and 2. A slight trend of increased attenuation with increasing temperature could be observed, especially at the higher frequencies (not shown). Similar to the effect of wind speed, turbulence could be responsible for this slight increase as higher air temperatures are usually accompanied with higher solar radiation during spring time in the region where the experiment took place. This trend is not sufficiently consistent to allow further analysis.

Relative humidity and air temperature are the major parameters influencing atmospheric absorption of sound in air. At the highest sound frequency considered, where the strongest effects are expected, the theoretical contribution of atmospheric absorption to the attenuation between microphone 1 and 2 ranges from $0.3 \mathrm{~dB}$ to $0.6 \mathrm{~dB}$, following ISO9613-1 [31]. So at the experimental site, the attenuation between microphone 1 and 2 is hardly influenced by atmospheric absorption at all sound frequencies considered.

\section{IV.Influence of soil moisture content on attenuation}

Soil moisture sensor 1 (the one closest to the roof edge) was used to perform this analysis. Very similar results are obtained when using sensor 2 (the one closest to microphone 2). Sensor 3 was not considered because it was inserted in the substrate later on during the experiment and would lead to a loss of data. Soil moisture readings were averaged over a period of one hour to be consistent with the other observations.

The boxplots in Fig. 6 show the effect of the VWC, expressed in 6 classes, on the sound attenuation for each 1/3-octave band considered in the experiment. Below $250 \mathrm{~Hz}$ and above $1.6 \mathrm{kHz}$, the effect of the substrate moisture content on the attenuation is very limited. Between $315 \mathrm{~Hz}$ and $1250 \mathrm{~Hz}$, the median of the sound attenuation decreases significantly with increasing volumetric water content class; so wet substrates perform significantly less in this frequency range. The effects are most pronounced at $315 \mathrm{~Hz}$ and $400 \mathrm{~Hz}$, where a difference in attenuation for the range of VWC measured approaches $10 \mathrm{~dB}$.

The limited effect at low frequencies is not surprising; the absorption coefficient of such substrates is limited, even under dry conditions, and the presence of water therefore has no big impact. At higher 
frequencies, characterized by a short wavelength, the elevated roof edge is expected to play an important role: sound could propagate more or less in a straight line from the roof edge towards microphone 2. Intermediate frequencies, on the other hand, sufficiently interact with the green roof substrate; sound waves can no longer be represented by the sound ray concept. At the same time, absorption coefficients of dry substrates are already quite high. At higher moisture contents, as discussed before, water fills pores, granules swell and clogging might occur, limiting the available space for sound propagating through the substrate. The latter is essential to benefit from absorption of acoustic energy.

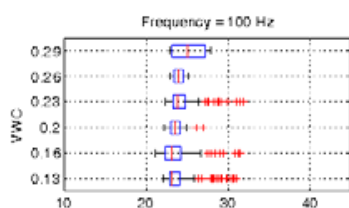

Frequency $=250 \mathrm{~Hz}$

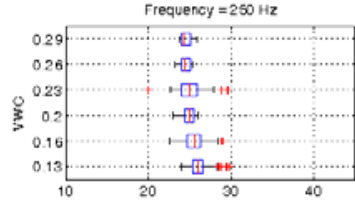

Frequency $=690 \mathrm{~Hz}$
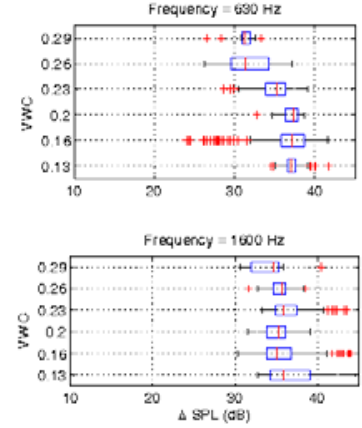

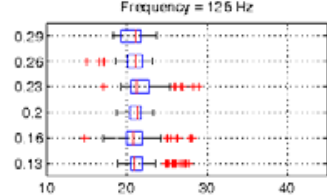

Frequenof $=315 \mathrm{~Hz}$

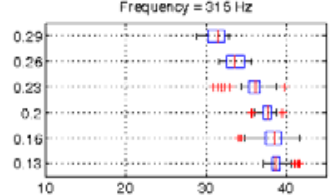

Frequenoy $=900 \mathrm{~Hz}$
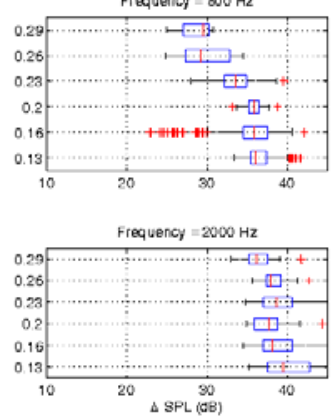

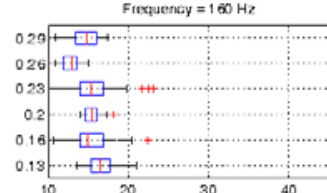

Frequency $=400 \mathrm{~Hz}$

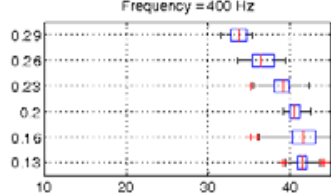

Frequency $=1000 \mathrm{~Hz}$
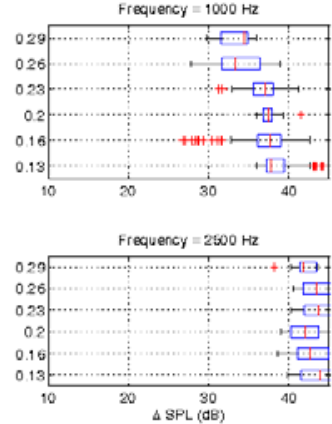

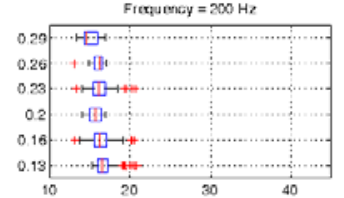

Frequency $=500 \mathrm{~Hz}$

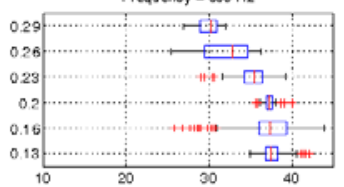

Frequency $=1250 \mathrm{~Hz}$

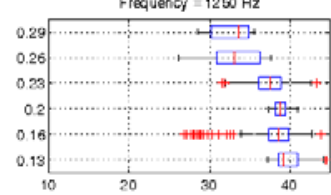

Frequency $=3150 \mathrm{~Hz}$

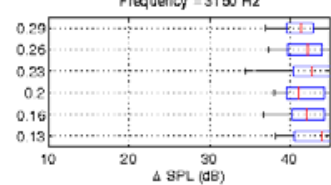

Fig. 6. Boxplots showing the distribution of the attenuations ( $\triangle \mathrm{SPL}$ ) over 6 different VWC classes $\left(\mathrm{in}^{3} / \mathrm{m}^{3}\right)$, over all 1/3-octave bands considered in the experiment. The (middle) horizontal lines in the boxes indicate the median of the data. The boxes are closed by the first and third quartile. The whiskers extend to 1.5 times the interquartile distance above the maximum value inside the box, and to 1.5 times the interquartile distance below the minimum value inside the box. Data points that fall outside these limits are indicated with the plus-signs.

Figure 7 shows that the effect of substrate VWC on attenuation can be well approached by a linear function. The Pearson's correlation coefficients are depicted as a function of frequency; the nocorrelation hypothesis could be rejected with $99 \%$ certainty at almost any frequency. The correlation coefficients are strongly dependent on the frequency, which is consistent with the description in previous paragraph. In addition, a rather gradual transition is observed between the frequencies where effects are observed and those where the influence of VWC is nearly absent. 


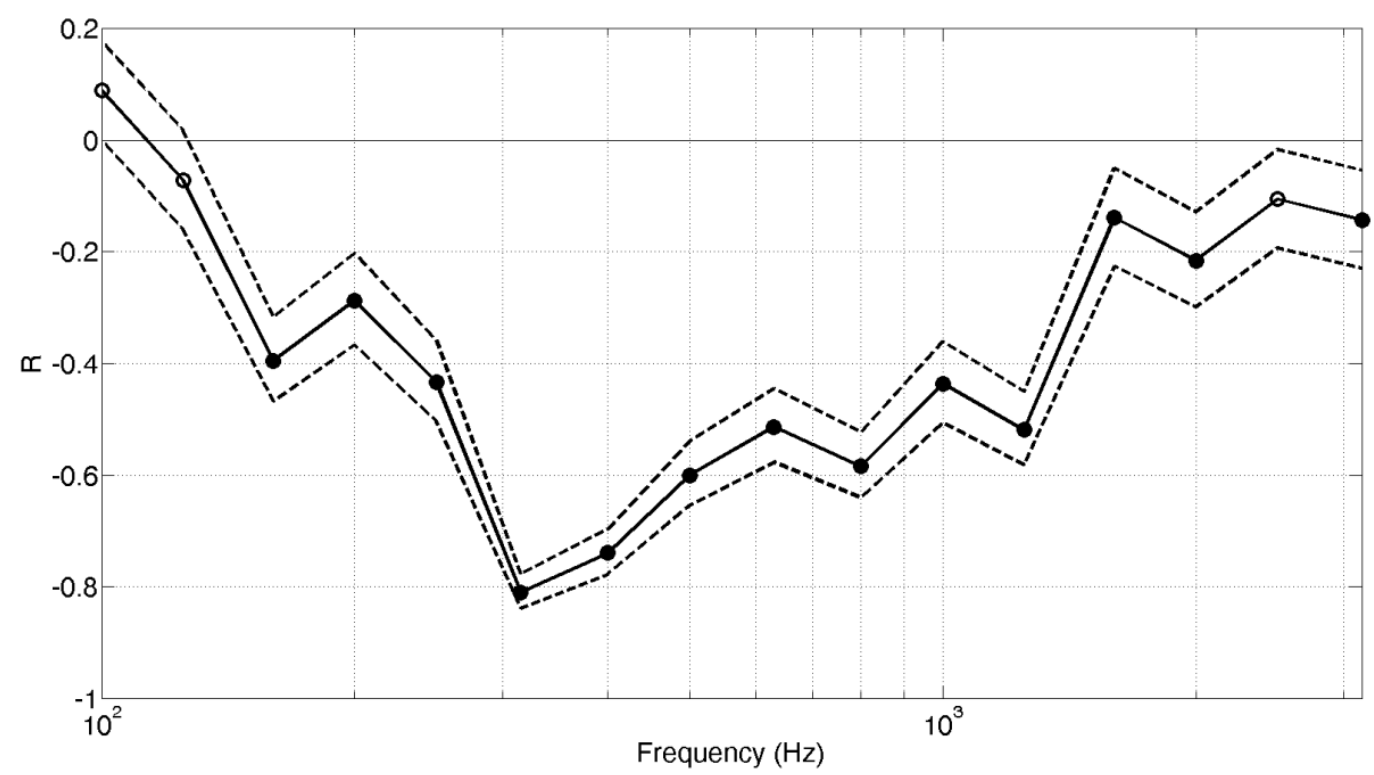

Fig. 7. Pearson's correlation coefficients between VWC and sound attenuation for the $1 / 3$-octave bands considered in the experiment. The distance between the upper and lower dashed lines indicates the $95 \%$-confidence intervals on the correlation coefficients. Filled black markers are used when the p-value for testing the hypothesis of "no correlation" could be rejected with $99 \%$ certainty.

\section{Artificial wetting experiment}

The artificial wetting experiment was performed at the moment the VWC (at sensor 1 ) measured a converged low value of $0.1 \mathrm{~m}^{3} / \mathrm{m}^{3}$. The last detected rainfall $(1 \mathrm{~mm})$ was 120 hours before the start of this additional experiment. Corresponding to the results presented in Fig. 6, when evaluating the medians, such substrate moisture content results in the highest attenuation that could be reached. Sound diffraction in this initial, dry state served as a reference for the attenuations at the 3 other moments during the deliberate moistening of the substrate. At the moments the sweeps were emitted, the moistening was stopped each time.

The findings are consistent with the continuous monitoring experiment : with increasing moisture content, the attenuation becomes lower in the frequency range between $250 \mathrm{~Hz}$ and $2000 \mathrm{~Hz}$, with maximum effects between $315 \mathrm{~Hz}$ and $1000 \mathrm{~Hz}$. The differences between the relative dry state $\left(V W C=0.1 \mathrm{~m}^{3} / \mathrm{m}^{3}\right.$ ) and the highest measured moisture content (saturation, $\mathrm{VWC}=0.33 \mathrm{~m}^{3} / \mathrm{m}^{3}$ ) amount up to $10 \mathrm{~dB}$ in this frequency range. Only in the most sensitive frequency range to moisture, roughly between $315 \mathrm{~Hz}$ and $600 \mathrm{~Hz}$, going to full water saturation of the substrate gave rise to further decreases in attenuation (relative to a VWC $=0.24 \mathrm{~m}^{3} / \mathrm{m}^{3}$ ). Below $250 \mathrm{~Hz}$ and above $2 \mathrm{kHz}$, a slight increase in attenuation is observed, but not monotonically with increasing moisture content.

Given the fact that this experiment was conducted during daytime, the signal-to-noise ratios were rather limited due to the presence of environmental noise. The signal-to-noise ratios (between $10.6 \mathrm{~dB}$ 
and $16.0 \mathrm{~dB}$ ) were therefore in the lower range relative to those from the continuous experiment, but still fulfilled the minimum criterion of $7.5 \mathrm{~dB}$. Each measurement (consisting of 5 emitted sweeps) was repeated two times and was linearly averaged to come to the attenuation spectra as presented in Fig. 8. The differences in attenuation between such repetitions were limited.

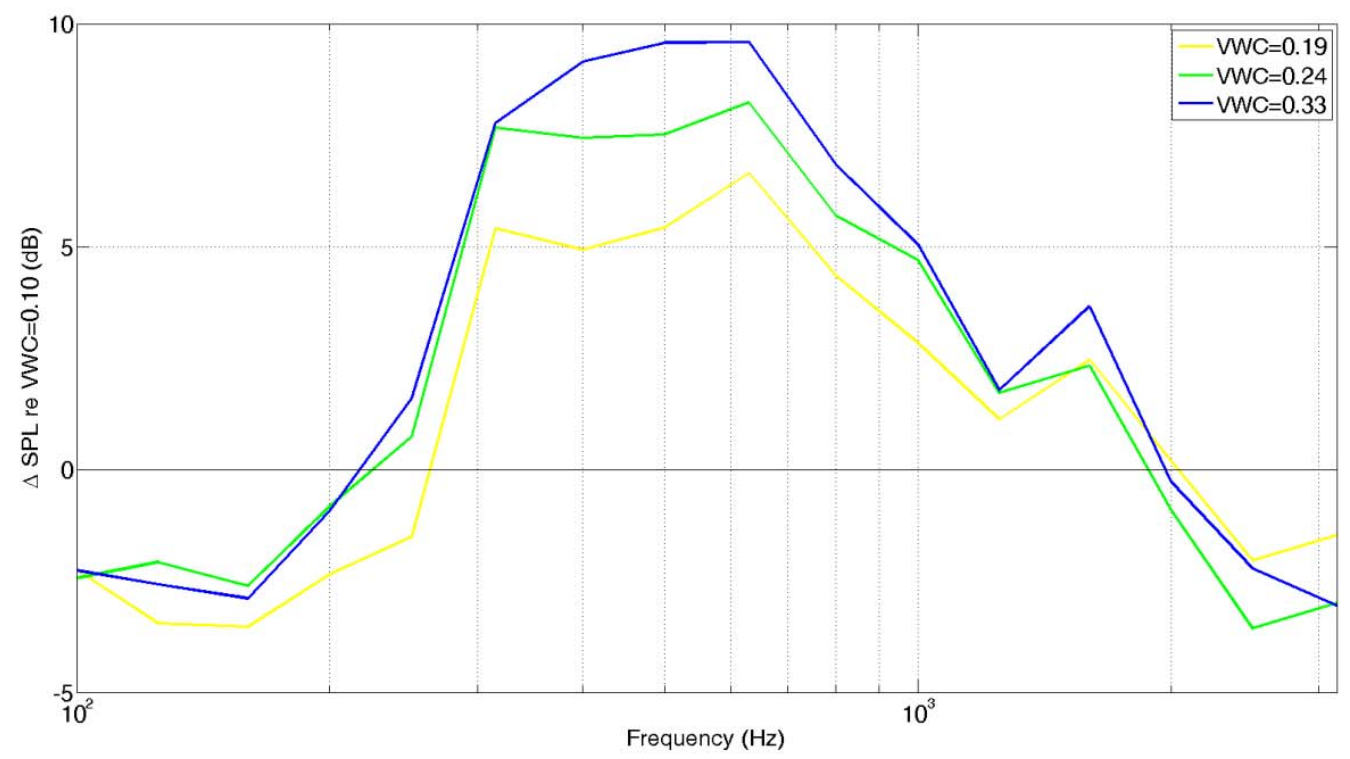

Fig. 8. Measured attenuation spectra, relative to the attenuation at a dry green roof $\left(\mathrm{VWC}=0.10 \mathrm{~m}^{3} / \mathrm{m}^{3}\right)$, during the artificial wetting experiment. The VWCs at moisture sensor 1 (in $\mathrm{m}^{3} / \mathrm{m}^{3}$ ) are shown. The VWC of $0.33 \mathrm{~m}^{3} / \mathrm{m}^{3}$ corresponds to near-saturation of the substrate.

\section{Simulated effect of rain on the shielding of road traffic noise}

The influence of rainfall on the sound pressure level at a shielded microphone (M2) is estimated in case of a hypothetical road traffic noise case. The period around April, 8 has been selected, as depicted in Fig. 5 , characterized by a period with heavy rainfall. The shielding provided by the roof's edge, the green roof absorption during diffraction (when dry), the effect of the substrate's moisture content on the acoustic absorption, road traffic noise and also the A-weighting, which is generally used to account for the sensitivity of the human ear in environmental acoustics, are all strongly frequency dependent. The influence of rainfall on the sound pressure level and its variation over time is therefore not obvious. The choice for road traffic is a logical one, as this is the most relevant and wide-spread environmental noise source in the urban environment, and it was shown before that this type of noise could be abated by a green roof [9][16].

The Harmonoise/Imagine road traffic source power model [32] provides road traffic noise spectra for light and heavy vehicles, at various vehicle speeds, in 1/3-octave bands. These power spectra were used to calculate an average (over vehicles) sound level at the shielded location at the moment when the sound level during the passage of the vehicle peaks, that is when the car is (virtually) located at the 
loudspeaker's position. As a reference, a sound pressure level of $65 \mathrm{dBA}$ is assumed at microphone 1 . The calculated course of the (maximum) sound pressure level at M2 in the selected period is depicted in Fig. 9

Linear regression functions were used to link the attenuation (per 1/3-octave band) between microphone 1 and 2 to the soil moisture content. The $p$-values corresponding to these linear correlations, as represented in Fig. 7, are sufficiently convincing to employ such a model. For the range of vehicle speeds between $30 \mathrm{~km} / \mathrm{h}$ and $120 \mathrm{~km} / \mathrm{h}$, and for light-to-heavy vehicle ratio's between 0 and 1 , the variation in acoustic shielding between the dry state $\left(V W C=0.1 \mathrm{~m}^{3} / \mathrm{m}^{3}\right)$, and maximum observed wetness due to rainfall, is predicted to range from $1.4 \mathrm{dBA}$ to $2.3 \mathrm{dBA}$. As a result, it can be concluded that the variation in acoustic shielding by a green roof due to rainfall will be rather limited in a typical road traffic configuration.

Clearly, this is a rather basic calculation exercise. The current monitoring experiment employs a single source position, corresponding to the maximum level at microphone 2 during a (virtual) passage of a vehicle. Consequently, oblique sound paths interacting with the green roof are not included. The effect of multi-lane road traffic is not accounted for as well. The calculations furthermore depend on idealized road traffic source power spectra.

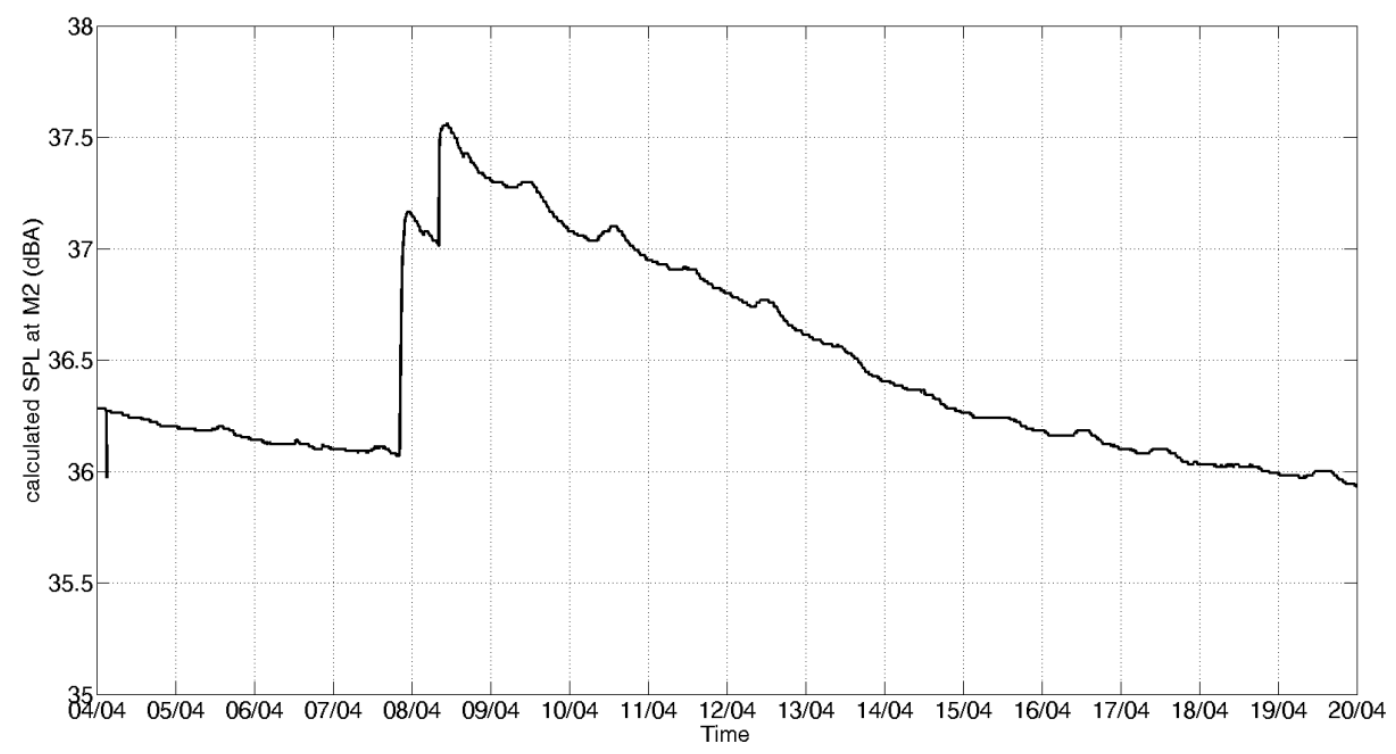

Fig. 9. Calculated maximum road traffic noise levels at $M 2$ around the period of the strong rainfall event at April, 8. The sound pressure level at M2 corresponds to a façade load of $65 \mathrm{dBA}$ (at M1); the vehicles are assumed to be positioned at the loudspeaker's position. Following traffic conditions were assumed : $80 \%$ light vehicles and $20 \%$ heavy vehicles, all driving at a uniform speed of $50 \mathrm{~km} / \mathrm{h}$.

\section{VII.Conclusions}


It has been shown in previous studies that green roofs could help reducing road traffic noise at the shielded side of a building, thereby creating a quiet side or at least improving the sonic environment. However, like any porous material or outdoor soil, the acoustic performance of the green roof's substrate could suffer from the presence of water. To quantify this effect, a 1.5-month lasting controlled sound propagation experiment was conducted near the edge of a building equipped with an extensive green roof. The sound pressure level difference between a reference microphone in front of the façade, close to an outdoor loudspeaker, and a microphone positioned on the green roof was monitored. A dedicated signal processing methodology was used for eliminating disturbing sound, ensuring a sufficient number of data points with a good signal-to-noise ratio. Sound level measurements were combined with on-site meteorological and substrate moisture measurements.

Sound diffracting over a green roof showed to be sensitive to the substrate moisture content in a specific frequency range, more precisely between $250 \mathrm{~Hz}$ and $1250 \mathrm{~Hz}$. The difference in noise attenuation between a rather dry state of the substrate and the maximum observed volumetric water content (close to saturation) ranges up to $10 \mathrm{~dB}$ in the current experimental setup. At low frequencies, the absorption coefficient is low anyhow and the presence of water has no impact. At high sound frequencies, the roof edge might exert an important role. Due to the strong frequency dependence of the effect of water content, averaging over a typical road traffic noise spectrum levels out the effect considerably. Based on the measured data for the specific extensive green roof under study, the impact of the substrate water content on A-weighted road traffic sound pressure level abatement is predicted to be less than $2 \mathrm{dBA}$. 


\section{References}

1. Oberndorfer E, Lundholm J, Bass B, Coffman R, Doshi H, Dunnett N, Gaffin S, Köhler M, Liu K, Rowe B. Green roofs as Urban Ecosystems: Ecological Structures, Functions, and Services. BioScience 2007; 57:823-833.

2. Berndtsson J. Green roof performance towards management of runoff water quantity and quality: A review. Ecological Engineering 2010;36:351-360.

3. Castleton $\mathrm{H}$, Stovin $\mathrm{V}$, Beck S, Davison J. Green roofs: building energy savings and the potential for retrofit. Energy and Buildings 2010;42:1582-1591.

4. Rowe D. Green roofs as a means of pollution abatement. Environmental Pollution 2011;159:2100-2110.

5. Cook-Patton S, Bauerle T. Potential benefits of plant diversity on vegetated roofs: A literature review. Journal of Environmental Management 2012;106:85-92.

6. Kang J, Huang $\mathrm{H}$, Sorrill J. Experimental study of the sound insulation of semi-extensive green roofs. In: Proceedings of the 38th international congress and exposition on noise control engineering (Internoise 2009), Ottawa, Canada.

7. Connelly $M$, Hodgson $M$. Experimental investigation of the sound transmission of vegetated roofs. Applied Acoustics 2013;74:1136-1143.

8. Van Renterghem T, Botteldooren D. Numerical evaluation of sound propagating over green roofs. Journal of Sound and Vibration 2008;317:781-99.

9. Van Renterghem T, Botteldooren D. Reducing the acoustical facade load from road traffic with green roofs. Building and Environment 2009;44: 1081-7.

10. Van Renterghem T, Botteldooren D. In-situ measurements of sound propagating over extensive green roofs. Building and Environment 2011:46:729-738.

11. Yang $H$, Kang J, Choi M. Acoustic effects of green roof systems on a low-profiled structure at street level. Building and Environment 2012;50:44-55.

12. Öhrström E, Skånberg A, Svensson H, Gidlöf-Gunnarsson A. Effects of road traffic noise and the benefit of access to quietness. Journal of Sound and Vibration 2006; 295: 40-59.

13. de Kluizenaar $Y$, Salomons E, Janssen S, van Lenthe F, Vos H, Zhou H, Miedema H, Mackenbach J. Urban road traffic noise and annoyance: The effect of a quiet façade. Journal of the Acoustical Society of America 2011;130:1936-1942.

14. Van Renterghem T, Botteldooren D. Focused study on the quiet side effect at dwellings highly exposed by road traffic noise. International Journal of Environmental Research and Public Health 2012;9:4292-4310.

15. Gidlöf-Gunnarsson A, Öhrström E. Attractive "quiet" courtyards: A potential modifier of urban residents' responses to road traffic noise? International Journal of Environmental Research and Public Health 2010;7:3359-3375.

16. Van Renterghem T, Hornikx M, Forssen J, Botteldooren D. The potential of building envelope greening to achieve quietness. Building and Environment 2013;61:34-44.

17. Dickinson P, Doak P. Measurements of the normal acoustic impedance of ground surface. Journal of Sound and Vibration 1970;13:309-322. 
18. Cramond A, Don C. Effect of moisture content on soil impedance. Journal of the Acoustical Society of America 1987;82:293-301.

19. Horoshenkov K, Mohamed M. Experimental investigation of the effects of water saturation on the acoustic admittance of sandy soils. Journal of the Acoustical Society of America 2006;120:1910-21.

20. Yang H, Kang J, Cheal C. Random-Incidence Absorption and Scattering Coefficients of Vegetation. Acta Acustica united with Acustica 2013;99:379-388.

21. Connelly M, Hodgson M. Laboratory experimental investigation of the acoustical characteristics of vegetated roofs. Journal of the Acoustical Society of America 2011;129:2393.

22. Villarreal E, Bengtsson L. Response of a Sedum green-roof to individual rain events. Ecological Engineering 2005;25:1-7.

23. Mentens J, Raes D, Hermy M. Green roofs as a tool for solving the rainwater runoff problem in the urbanized 21st century? Landscape and Urban Planning 2006;77:217-226.

24. Teemusk A, Mander U. Rainwater runoff quantity and quality performance from a green roof: The effects of short-term events. Ecological Engineering 2007;30:271-277.

25. Bliss D, Neufeld R, Ries R. Storm water runoff mitigation using a green roof. Environmental Engineering Science 2009;26:407-417.

26. Morgan S, Celik S, Retzlaff W. Green Roof Storm-Water Runoff Quantity and Quality. Journal of Environmental Engineering 2013;139:471-478.

27. Sakaki T, Limsuwat A, Smits K, Illangasekare T. Empirical two-point A-mixing model for calibrating the ECH2O EC-5 soil moisture sensor in sands. Water Resources Research 2008;44:W00D08.

28. Van Renterghem T, Botteldooren D. Meteorological influence on sound propagation between adjacent city canyons: a real-life experiment. Journal of the Acoustical Society of America 2010;127:3335-3346.

29. Ribeiro C, Ecotière D, Cellard P, Rosin C. Uncertainties of the frequency response of wet microphone windscreens. Applied Acoustics 2014;78:11-18.

30. Forssén J, Ögren M. Thick barrier noise-reduction in the presence of atmospheric turbulence: measurements and numerical modelling. Applied Acoustics 2002;63:173-187

31. ISO 9613-1. Acoustics - attenuation of sound during propagation outdoors - part 1. International Organisation for Standardisation, Geneva, Switzerland, 1996.

32. Jonasson H. Acoustical source modelling of road vehicles. Acta Acustica united with Acustica 2007;93:173-84. 